\title{
What's in a test?
}

\section{Customers of genetic and genomic services need better education even more than tighter regulation.}

The last three years have seen an expansion in direct to consumer (DTC) genetic services, from those that offer single-gene tests to companies that screen a customer's DNA at various loci for polymorphisms associated with certain diseases or even, for a hefty fee, offer wholegenome sequencing. For the first time the lay public has direct access to methods and data previously limited to professionals. This has raised concerns among public health and consumer advocates as well as governmental institutions and has led to calls for tighter regulation.

Critics are concerned about the analytical validity: that the tests perform accurately; the clinical validity: that the genetic variants tested for are associated with increased disease risk; and the clinical utility: that the information is helpful for the consumers.

Different countries have approached these concerns differently. In the US, with little federal oversight, regulation is largely up to the states and varies widely. In Germany, a recent law (Gesetz über genetische Untersuchung bei Menschen) in essence bans DTC genetic testing, and mandates that only physicians can order genetic tests and that the interpretation of the results must be bundled with counseling. In contrast, the House of Lords' Science and Technology committee in the UK issued a report in July on genomic medicine proposing self-policing by the industry.

Which is the right approach? There may not be a single answer for all DTC genetic tests. A DTC test that screens for a specific mutation implicated in a highrisk disease such as cancer or a disease that could affect one's children requires different considerations than DTC genomic services that test a wider range of loci with more uncertain links to diseases.

But in either case, restrictive regulations have drawbacks. For one, they are hard to enforce. It is difficult to envisage how they can be upheld with companies that sell their services over the internet. And what is to prevent the companies from following the letter rather than the spirit of the law? By partnering with healthcare providers that order the tests for a consumer, DTC companies could circumvent the mandate for physician involvement. Requiring a physician means that the cost of the tests will always be high, even if the technology becomes very cheap.

Are special regulations for DTC genetic services even necessary, or are existing 'truth in advertising' laws sufficient? Current US laws regulating the promotion of services can be enforced through statutory bodies like the Federal Trade Commission. If, for example, a company made untrue claims about clinical validity of its tests, the Federal Trade Commission could step in and either prohibit these claims or issue specific consumer alerts.

Do people really need to be protected from learning their genetic makeup firsthand? Advocates for DTC testing argue that the information is not as 'toxic' as some fear, often citing a recent study by the Reveal study group, which showed that learning about an increased risk for Alzheimer's disease did not increase depression and anxiety in test subjects. Although it may be true that people can handle bad news very well, it is important to note that the Reveal study has its biases. As Robert Cook-Deegan, a member of the Reveal study group, pointed out, all test subjects received pretest counseling, and people with a history of anxiety or depression were not included. So there is as of yet no indication of what the societal impact of DTC genetic testing will be.

Companies could do their share to alleviate concerns. Sponsorship of a public database with research-based evidence supporting associations between genes and diseases with tools to view and interpret the DTC data would go a long way. Importantly, the privacy of the information needs to be safeguarded.

But the onus is also on consumers to educate themselves about what DTC genetic services do and do not offer. In the case of tests for a single mutation known to be associated with a disease, it is important to look at the details of the science involved. For example, mutations in BRCA1 and BRCA2 mainly indicate elevated risk of breast cancer in women with a family history of the disease. In the case of DTC genomic tests, the increased disease risk owing to certain alleles is often very small. There needs to be an understanding that genotyping or sequencing data should not be a node in the decision tree to medical intervention. Rather this information should form the basis for a more detailed talk with a physician or genetic counselor.

With sequencing costs dropping, it is likely that DTC genetic services will soon include affordable wholegenome sequencing. Consumers who have familiarized themselves with the limitations of these data will be better equipped for the 3 gigabases of information that may soon come their way.

Corrected online 16 November 2009. 


\section{Erratum: What's in a test?}

Anonymous

Nat. Methods 6, 783 (2009); published online 29 October 2009; corrected after print 16 November 2009

In the version of this article initially published, the name of Robert Cook-Deegan was misspelled. The error has been corrected in the HTML and PDF versions of the article. 